Canadian

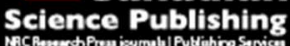

Applied Physiology, Nutrition, and Metabolism Physiologie appliquée, nutrition et métabolisme

\title{
EFFECTS OF AN ACUTE BOUT OF MODERATE INTENSITY EXERCISE ON POSTPRANDIAL LIPEMIA AND AIRWAY INFLAMMATION
}

\begin{tabular}{|r|l|}
\hline Journal: & Applied Physiology, Nutrition, and Metabolism \\
\hline Manuscript ID & apnm-2015-0314.R2 \\
\hline Manuscript Type: & Article \\
\hline Date Submitted by the Author: & $29-$-Oct-2015 \\
\hline Complete List of Authors: & $\begin{array}{l}\text { Johnson, Ariel; Kansas State Univerisity, Kinesiology } \\
\text { Kurti, Stephanie; Kansas State Univerisity, Kinesiology; } \\
\text { Smith, Joshua; Kansas State University, Kinesiology } \\
\text { Rosenkranz, Sara; Kansas State University, Human Nutrition } \\
\text { Harms, Craig; Kansas State University }\end{array}$ \\
\hline Keyword: & $\begin{array}{l}\text { inflammation, exercise < exercise, pulmonary physiology < physiology, } \\
\text { dyslipidemia, exercise metabolism < exercise metabolism }\end{array}$ \\
\hline &
\end{tabular}


EFFECTS OF AN ACUTE BOUT OF MODERATE INTENSITY EXERCISE ON POSTPRANDIAL LIPEMIA AND AIRWAY INFLAMMATION

Ariel M. Johnson, Stephanie P. Kurti, Joshua R. Smith, Sara K. Rosenkranz, Craig A. Harms

Corresponding author: Stephanie P. Kurti

A.M. Johnson · S.P. Kurti (*) · J.R. Smith · C. A. Harms

Department of Kinesiology, Kansas State University, 1A Natatorium, Manhattan, KS 66506, USA

e-mail: stephkurti@ksu.edu

Phone: 785-215-3573

Fax: 785-532-6486

S. K. Rosenkranz

Department of Human Nutrition, Kansas State University, Manhattan, KS, USA 


\begin{abstract}
A high-fat meal (HFM) induces an increase in blood lipids (postprandial lipemia; PPL), systemic inflammation, and acute airway inflammation. While acute exercise has been shown to have anti-inflammatory and lipid lowering effects, it is unknown whether exercise prior to a HFM will translate to reduced airway inflammation post-HFM. Our purpose was to determine the effects of an acute bout of exercise on airway inflammation post-HFM and to identify whether any protective effect of exercise on airway inflammation was associated with a reduction in PPL or systemic inflammation. In a randomized cross-over study, 12 healthy 18-29 year old men (23.0 $3.2 \mathrm{yrs}$,

$178.9 \pm 5.5 \mathrm{~cm} 78.5 \pm 11.7 \mathrm{~kg}$ ) consumed a HFM (1g fat $/ 1 \mathrm{~kg}$ body weight) 12 hours following exercise (EX; $60 \mathrm{~min}$ at $\left.60 \% \dot{\mathrm{V}}_{2} \max \right)$ or without exercise $(\mathrm{CON})$. Fractional exhaled nitric oxide $\left(\mathrm{FE}_{\mathrm{NO}}\right.$; measure of airway inflammation), triglycerides (TG) and inflammatory markers (high-sensitivity C-reactive protein (hsCRP), tumor-necrosis factoralpha (TNF- $\alpha$ ), interleukin-6 (IL-6)) were measured while fasted, two hours and four hours post-HFM. FE $\mathrm{NO}_{\mathrm{NO}}$ increased over time ( $2 \mathrm{HR}$ : CON, $\mathrm{p}=0.001 ; \mathrm{EX}, \mathrm{p}=0.002$, but not by condition ( $\mathrm{p}=0.991)$. TG significantly increased two and four hours post-HFM ( $p<0.001)$, but was not significant between conditions $(p=0.256)$. Inflammatory markers did not significantly increase by time or condition $(\mathrm{p}>0.05)$. There were no relationships between $\mathrm{FE}_{\mathrm{NO}}$ and TG or systemic inflammatory markers for any time point or condition ( $p>0.05)$. In summary, an acute bout of moderate intensity exercise performed 12 hours prior to a HFM did not change postprandial airway inflammation or lipemia in healthy, 18-29 year old men.
\end{abstract}

Keywords: inflammation, exercise, pulmonary physiology, dyslipidemia, exercise metabolism 


\section{Introduction}

High-fat diets are known to be a risk factor for cardiovascular disease, and even a single high-fat meal (HFM) increases circulating TG (post-prandial lipemia; PPL) and circulating pro-inflammatory cytokines. This postprandial inflammation is a shared risk factor for several chronic diseases, including obesity and asthma. These diseases are commonly expressed in the same individuals, and late-onset asthma commonly experienced in obese individuals, may be due to the effect of high-fat diets on the airways. Even a single HFM has been shown to increase inflammation in the airways (Rosenkranz et al., 2010; Wood et al., 2011, Ade et al., 2014; Kurti et al., 2015), and not just systemically. Recent research has reported a transient increase $(\sim 20 \%)$ in airway inflammation two hours following the consumption of a single high fat meal (HFM) in non-asthmatic subjects (Rosenkranz et al. 2010). This finding has been confirmed four hours post-HFM in healthy non-asthmatics (Kurti et al. 2015) and asthmatics (Wood et al., 2011). Although the mechanisms behind increases in airway inflammation post-HFM are not completely understood, several mechanisms may increase exhaled nitric oxide. The mechanisms that may be involved are both TLR4-dependent and TLR4-independent (Teng et al., 2014). In TLR4-dependent pathways, lipopolysaccharide (LPS) from the HFM has been shown to increase TLR4 mRNA via a nuclear factor-kappa B (NFkB) driven cascade (Wood et al., 2011), and increase neutrophil influx into the airways (Kurti et al., 2015). However the activation of NFkB from high-fat diets may occur due to TLR4-indpendent pathways as well (Zhang et al., 2005). Sugita and colleagues (2002) showed that in rats injected with LPS, inducible nitric oxide synthase expression was increased. Dietary fats may increase reactive oxygen species (ROS), therefore increasing transcription factors NFkB and IkB kinase $\beta$ (IKK $\beta$ ) (Kim et al., 2010) which upregulate iNOS, contributing to the increase in exhaled nitric oxide (Ricciardolo et al., 2004). The inducible NO isoform may become activated in the airways, which may contribute to the increase in exhaled nitric oxide (Gaston et al. 1994).

Recent research has shown dietary supplementation may be protective against increases in post-prandial airway inflammation (Ade et al. 2014), due to a lower sensitivity to a HFM stimulus. Along with adaptations occurring with chronic exercise training, an acute bout of exercise also increases antioxidant enzyme capability (Kramer and Goodyear 2007). However, unlike fish oil or anti-oxidant supplementation, exercise is also known to reduce PPL and also stimulates an anti-inflammatory cascade of cytokines, thereby potentially further lowering the sensitivity to the HFM stimulus and possibly attenuating the inflammatory response to a HFM. It is well established that a single bout of exercise can attenuate PPL (Freese et al. 2014; Gill and Hardman 2003). This attenuation is 
generally thought to be an acute response, dependent on both the timing of the exercise bout and the energy expended during the bout. Exercise performed 12-16 hours before consumption of a HFM has been shown to be effective in reducing PPL (Zhang et al. 1998). Additionally, an acute bout of exercise stimulates a unique antiinflammatory cascade of cytokines beginning with an increase in IL-6 from the contracting muscle (Petersen and Pedersen 2005). In addition to acute effects from exercise, chronic physical activity contributes to an overall antiinflammatory environment systemically, as well as in the airways. Lowder et al., 2010 showed that there were increased baseline levels of the anti-inflammatory cytokine IL-10 following a training intervention in mice. Additionally Rodriguez-Mendez (2011) showed a decreased baseline eosinophilic inflammation and decreased $\mathrm{FE}_{\mathrm{NO}}$ after a training intervention in humans. Although PPL and airway inflammation have not been consistently associated (Rosenkranz et al., 2010; Ade et al., 2014; Kurti et al. 2015), both independent risk factors for disease are modifiable with acute exercise. Therefore an acute bout of exercise prior to a HFM may reduce TG, systemic and airway inflammation post-prandially due to lipid modifying, and anti-inflammatory properties.

With both lipid lowering and systemic anti-inflammatory effects, exercise performed before a HFM may provide a protective effect against post-prandial airway inflammation. Therefore, the purpose of this study was to investigate the effect of a single continuous bout of aerobic exercise prior to a HFM on the airway inflammatory response. Additionally, we were interested in identifying whether changes in airway inflammation were associated with changes in PPL or systemic inflammation. We hypothesized that an acute bout of aerobic exercise 12 hours prior to a HFM would protect against subsequent airway inflammation in healthy men and further, would be associated with changes in PPL and systemic inflammation.

\section{Materials and Methods}

\section{Subjects}

Twelve 18 to 29 year old men volunteered to participate. Subjects were recreationally active but none were competitively training. All subjects were non-smokers and had apparently healthy pulmonary, metabolic, and cardiovascular function as determined by medical questionnaire. All subjects had normal pulmonary function and normal fasting blood lipid and glucose levels as determined by standard pulmonary function tests and intravenous blood sampling. Subjects were not using any medications or dietary supplements including antioxidant and fish oil supplementation throughout the course of the study. Verbal and written consent was obtained from all subjects. The 
study was approved by the Institutional Review Board for Research Involving Human Subjects at Kansas State University, and conformed to the Declaration of Helsinki.

\section{Experimental Design}

Subjects visited the laboratory on three separate occasions. On the first visit, height, weight, and body composition via dual-energy x-ray absorbtiometry (DXA) were measured (Preliminary measures). Subjects then performed a $\dot{\mathrm{V}} \mathrm{O}_{2}$ max test on an electronically braked cycle ergometer to determine the appropriate intensity for sub-maximal exercise in the experimental condition. On two subsequent visits (day 1 or 2), subjects performed one of two trials separated by at least seven days in a randomized cross-over study design: control trial (high-fat meal only; CON) and an exercise trial $12 \mathrm{~h}$ before the high fat meal (EX). The experimental design is displayed in Figure 1.

\section{Preliminary Measures}

On the subjects' first visit to the laboratory, height and weight were recorded on a standard physician scale and body composition was measured via dual-energy x-ray absorbtiometry (v5.6, GE Lunar Corp., Milwaukee, WI, USA). Subjects them completed an incremental test to exhaustion to determine maximal aerobic capacity.

\section{Maximal Aerobic Capacity}

An incremental exercise test was performed on an electronically braked cycle ergometer (Sensormedics 800, Sensormedics Corp., YorbaLinda, CA). Metabolic and ventilatory data were collected and analyzed on a breath-bybreath basis (Sensormedics 229 Metabolic Cart, Sensormedics Corp., YorbaLinda, CA). Heart rate was monitored continuously using a chest strap heart rate monitor (Polar T31-Uncoded, Polar). Arterial oxygen saturation $\left(\mathrm{SpO}_{2}\right)$ was estimated via a pulse oximeter (Datex-Ohmeda 3900P, Madison, WI). A modified Borg's rating of perceived exertion (RPE) scale, values of 1-10, were recorded at each exercise stage. After three minutes of rest and baseline measurements, subjects maintained a pedaling frequency of $60-80 \mathrm{rpm}$ beginning at a work rate of $50 \mathrm{~W}$ and increasing $25 \mathrm{~W}$ every minute until exhaustion. Subjects were verbally encouraged to achieve the highest work rate possible. The highest $\mathrm{O}_{2}$ consumption averaged over 15 seconds was considered the $\mathrm{V}_{2}$ max. After resting for 15 min, $\dot{\mathrm{V}}_{2}$ max was verified (Poole et al. 2008) by setting the work rate at $105 \%$ of the work rate corresponding to $\dot{\mathrm{V}} \mathrm{O}_{2}$ max. Subjects pedaled at 60-80 rpm until exhaustion. If subjects failed to pedal for at least two minutes, or did not achieve a $\dot{\mathrm{VO}}_{2}$ within the range of $10 \mathrm{ml} \mathrm{O}_{2} \mathrm{~W}^{-1}$, validation criteria were not met and a repeated full test was scheduled for a later date. Ventilatory threshold (VT) was estimated by three blinded researchers using the V-slope 
method (Beaver et al. 1986) to determine if subjects exercised above or below their threshold and whether this influenced their results.

Day 1 - Exercise or rest and standardization of diet

In the control condition, subjects reported to the lab after a $12 \mathrm{~h}$ fast. Subjects abstained from exercise, caffeine and alcohol consumption for $24 \mathrm{~h}$ before the trial. In addition, subjects were asked to record their diet for the $24 \mathrm{~h}$ period before the trial. They repeated this diet in the $24 \mathrm{~h}$ prior to fasting measurements for the experimental trial. For the experimental trial, subjects reported to the laboratory 12 hours prior to the time they would come in for their day 2 visit. On their exercise test (between $5 \mathrm{pm}$ and $9 \mathrm{pm}$ ), 12 hours before fasting measurements subjects performed one hour of cycling at $60 \%$ of $\dot{\mathrm{V}}_{2} \max$ (Magkos et al., 2007). Metabolic and ventilatory data were collected breath-bybreath continuously throughout the bout (Sensormedics 229 Metabolic Cart, Sensormedics Corp., YorbaLinda, CA). Heart rate was recorded every three minutes using a chest strap heart rate monitor (Polar T31-Uncoded, Polar). Subjects fasted for 12 hours immediately after exercise.

Day 2- Return to laboratory after rest or exercise session

Upon reporting to the lab (between 5 am and 9 am), a battery of fasting blood analyses and pulmonary tests were performed. These are described in detail below. After completion of fasting testing, subjects consumed the HFM. The HFM was identical in the CON and EX trial. In EX, the meal was consumed 12 hours after the start of the exercise bout. Measures identical to those performed while fasted were repeated at 2- and 4-h postprandially. High Fat Meal

The HFM used in the present study was identical to that previously employed by Rosenkranz et al. (2010) and Ade et al. (2014). The meal consisted of a fat dose equivalent to $1 \mathrm{~g}$ fat per $\mathrm{kg}$ bodyweight and was composed of ice cream (Edy's Grand Vanilla) and whipping cream (Reddi wip original). Ice cream serving size was measured as ml of ice cream $=$ bodyweight in $\mathrm{kg} \times 4.0625$. Whipping cream was measured as $\mathrm{mL}$ of whipped cream $=$ bodyweight in $\mathrm{kg} \times 1.5$. The nutritional makeup of the HFM was $7 \mathrm{~g}$ of total fat, with $4 \mathrm{~g}$ from saturated fat per serving. An additional 3 grams were from polyunsaturated and monounsaturated fat. There were 140 calories per serving, and 16 grams of carbohydrate with 13 grams from sugar per serving. There were an additional 2 grams of protein and 30 $\mathrm{mg}$ cholesterol per serving. The meal was ingested within a 20 min timeframe from the first bite.

Pulmonary Function Measures 
Pulmonary tests carried out at baseline and 2- and 4-h postprandially in all conditions consisted of standard pulmonary function tests (PFTs; forced vital capacity (FVC), forced expiratory flow in 1-s $\left(\mathrm{FEV}_{1}\right)$, forced expiratory flow at $25-75 \%$ of vital capacity $\left.\left(\mathrm{FEF}_{25-75}\right)\right)($ SensorMedics 229 Metabolic Cart, Sensor MedicsCorp., Yorba Linda, $\mathrm{CA})$, fractional exhaled nitric oxide tests $\left(\mathrm{FE}_{\mathrm{NO}}\right)$ as a marker of airway inflammation via chemilluminescence (Sievers Nitric Oxide Analyzer 280, Sievers Instruments Inc, Boulder, CO, USA), and impulse oscillometry (IOS, Jaeger, Germany) as a measure of airway resistance. All PFTs were performed in triplicate with maximal values used in analysis according to American Thoracic Society guidelines (Pellegrino et al. 2005). $\mathrm{FE}_{\mathrm{NO}}$ tests were performed in triplicate with average values used in analysis.

Blood Sampling and Biochemical Assays

CRP, TNF- $\alpha$, IL-6, blood lipid profiles, and blood glucose were determined while fasted and 2- and 4-h after the consumption of the HFM in all conditions via serial blood draws using an intravenous catheter. A $1 \mathrm{~L}$ saline bag containing $0.9 \% \mathrm{NaCl}$ was allowed to flow into the vein at a drip rate of one per second. A waste sample of $3 \mathrm{ml}$ was extracted in order to clear any saline from the sampling line. At each time point, $5 \mathrm{ml}$ blood samples were collected in a disposable syringe. $40 \mu \mathrm{l}$ samples were collected from the syringe in sterile lithium heparin coated capillary tubes within 10 seconds. The remainder of the sample was transferred to a $6 \mathrm{~mL}$ K2EDTA vacutainer and centrifuged to separate plasma from red blood cells. Plasma was removed and frozen at $-60^{\circ} \mathrm{C}$.

TC, HDL, LDL, TG, and blood glucose were analyzed using a Cholestech LDX analyzer (Alere San Diego Inc., San Diego, CA). Commercial ELISAs were used to measure IL-6 and TNF- $\alpha$ (Cayman Chemical Company, Ann Arbor, MI) and high-sensitivity C-reactive protein (hsCRP; BQ Kits, Inc., San Diego, CA). Absorbance was read using a microplate reader (Synergy HT Multi-Mode Microplate Reader, Biotek Instruments Inc., Winooski, VT). Intra-assay coefficients of variation for TNF- $\alpha$ were $6.6 \%, 2.9 \%$ for CRP, and 5.06\% for IL-6. For each assay, standards were plated in duplicate and samples were plated singly.

\section{Statistical Analysis}

Data analyses were conducted using SPSS v22.0 Statistics (IBM Corporation, Armonk, NY). Data were checked for normality, and if parametric assumptions were not met, data were $\log 10$ transformed prior to analysis. Data are expressed as mean $\pm \mathrm{SD}$. Two-way repeated measures ANOVA with time (fasted, 2-, and 4- hour time points) and condition (CON, EX) as independent factors was used. Tukey post-hoc tests were carried out for significant effects. 
Magnitudes of responses were quantified as peak and incremental area under the curve (iAUC) responses. Relationships were determined via linear regression. Significance was set at $\mathrm{p}<0.05$ for all analyses.

\section{Results}

Subjects

Subject characteristics are shown in Table 1. All subjects were non-obese $(\mathrm{BMI}<30)$. The average $\dot{\mathrm{V}}_{2} \mathrm{max}$ was $46.9 \pm 7.9 \mathrm{~mL} \mathrm{~kg}^{-1} \mathrm{~min}^{-1}$. During the exercise bout, mean $\dot{\mathrm{VO}}_{2}$ was $26.7 \pm 3.8 \mathrm{~mL} \mathrm{~kg}^{-1} \mathrm{~min}^{-1}(57.4 \pm 6.1 \%$ of $\dot{\mathrm{VO}}_{2} \mathrm{max}$ ) and $623 \pm 74 \mathrm{kcal}$ of energy were expended. Six subjects exercised below their ventilatory threshold (VT) and six exercised above VT but the groups did not show a different response in main outcome variables based on VT.

\section{Exhaled Nitric Oxide}

Mean and individual $\mathrm{FE}_{\mathrm{NO}}$ responses are shown in Figure 2. $\mathrm{FE}_{\mathrm{NO}}$ while fasted was not different between $\mathrm{CON}$ and $\mathrm{EX}$ conditions $(\mathrm{p}=0.853)$. $\mathrm{FE}_{\mathrm{NO}}$ increased $\sim 18 \%$ two hours after consuming the HFM in both conditions $(\mathrm{p}<0.05)$. In each condition, 11 of the 12 subjects increased $\mathrm{FE}_{\mathrm{NO}} 2$ hours postprandially (CON: $\mathrm{p}=0.001$; EX: $\mathrm{p}=0.002)$. Four hours postprandially, $\mathrm{FE}_{\mathrm{NO}}$ was not significantly different from baseline values in $\mathrm{EX}(\mathrm{p}=0.145)$ and remained elevated in $\mathrm{CON}(\mathrm{p}=0.043)$. However there was no significant difference in $\mathrm{FE}_{\mathrm{NO}}$ between conditions (0.991).

\section{Blood Analytes}

Mean blood analyte values for each condition and time point are shown in Table 2. EX blood lipid profiles were significantly higher in EX compared to CON ( $\mathrm{p}=0.011)$. TG response is shown in Figure 3A. Individual responses are shown in Figures 3B and 3C. In both conditions, TG were significantly elevated at 2- and $4 \mathrm{~h}$ postprandially $(\mathrm{p}<0.001)$. Triglycerides did not differ between conditions $(\mathrm{p}=0.256)$, however there was a significant interaction between time and condition $(\mathrm{p}=0.016)$. There were no significant differences in incremental triglyceride iAUC ( $p=0.075$ ) however the 95\% CI's show EX triglycerides were lower than CON (EX: 51.6219-113.3781 $\mathrm{mg} / \mathrm{dL}$; CON: 81.435-171.398 mg/dL) (Figure 4). LDL did not significantly change in either condition (CON: $p=0.306 ; E X: p=0.208)$. CON and EX values did not differ from each other $(p>0.05)$. Blood glucose was significantly lower than baseline at two hours post-HFM in both conditions $(\mathrm{p}=0.005)$. There were no changes in TC or HDL across time for either condition ( $\mathrm{p}>0.05$ ). In the exercise condition, changes in blood lipids were not related 
to energy expended in the bout at baseline to two hours $(p=0.444)$ or four hours $(p=0.202)$ There were no significant relationships between changes in blood lipids and $\mathrm{FE}_{\mathrm{NO}}$ from baseline to two or four hours $(\mathrm{p}=0.911$ and $\mathrm{p}=0.472$, respectively) or glucose and $\mathrm{FE}_{\mathrm{NO}}(2 \mathrm{hr}, \mathrm{p}=0.596 ; 4 \mathrm{hr}, \mathrm{p}=0.663)$, respectively).

\section{Inflammatory Markers}

Mean values for hsCRP, TNF- $\alpha$, and IL-6 are shown in Table 2. Inflammatory markers hsCRP and IL-6 were normally distributed, while TNF- $\alpha$ was not normally distributed and log-transformed prior to analysis. Mean fasting hsCRP was not different between conditions $(\mathrm{p}=0.194)$. All subjects were within the healthy range of hsCRP $\left(<3.0 \mathrm{mg} \mathrm{L}^{-1}\right)$ for the CON condition. Only one subject fell outside of this range in the $\mathrm{EX}$ condition $(\mathrm{hsCRP}=3.37$ $\left.\mathrm{mg} \mathrm{L}^{-1}\right)$. There were no changes ( $\left.\mathrm{p}>0.05\right)$ in hsCRP between time points or conditions (see Figure $5 \mathrm{~A}$ ).

Mean fasting concentration of TNF- $\alpha$ in the CON and EX conditions were not different from each other ( $p$ $\mathrm{p}=0.859)$. Mean IL-6 concentrations while fasted were not significantly different $(\mathrm{p}=0.796)$. There was no change in concentration of IL-6 or TNF- $\alpha$ over time or condition (see Figures $5 \mathrm{~B}$ and $5 \mathrm{C} ; \mathrm{p}>0.05$ ). There were no significant relationships between inflammatory markers and $\mathrm{FE}_{\mathrm{NO}}$ or $\mathrm{TG}$ (all p values $>0.05$ ).

\section{Pulmonary Function}

Mean data for pulmonary function is shown in Table 3 . In the EX condition, $\mathrm{FEV}_{1} / \mathrm{FVC}$ was significantly higher than CON at $4 \mathrm{~h}$ only $(\mathrm{p}=.001)$. Additionally, within the EX condition, $\mathrm{FEV}_{1} / \mathrm{FVC}$ was higher at $4 \mathrm{~h}$ compared to $2 \mathrm{~h}(\mathrm{p}=.025)$; however, there were no differences in $\mathrm{FEV}_{1}$ or FVC individually within or between conditions ( $p>0.05)$. There were no changes $R_{\text {central }}$ or $R_{\text {periph }}$ between condition $(p=0.981)$ or time points $(C O N$ : $\mathrm{p}=0.371$; EX: $\mathrm{p}=0.272$ ). There were no significant relationships between pulmonary function and $\mathrm{FE}_{\mathrm{NO}}$ or $\mathrm{TG}(\mathrm{all}$ p-values $>0.05)$.

\section{Discussion}

Major Findings

The purpose of this study was to investigate the effect of a single continuous bout of aerobic exercise on postprandial airway inflammation. Our data suggest that an acute bout of moderate intensity exercise twelve hours prior to consumption of a HFM, was not effective in reducing airway inflammation post-HFM, nor were there 
associations between changes in PPL and changes in systemic or airway inflammation. Despite this lack of a protective effect for airway inflammation, it is important to consider the potential mechanism by which a single HFM increases airway inflammation, particularly considering that there were no associations between changes in PPL and airway inflammation at any time point.

Postprandial airway inflammation- possible mechanisms

Previous research has shown that a HFM leads to a significant increase in airway inflammation (exhaled nitric oxide; $\mathrm{FE}_{\mathrm{NO}}$ ) two hours postprandially (Ade et al. 2014; Rosenkranz et al. 2010). The fasting $\mathrm{FE}_{\mathrm{NO}}$ values of our subjects ( $\sim 36 \pm 23.3 \mathrm{ppb}$ ) were considerably higher compared to previously reported $\mathrm{FE}_{\mathrm{NO}}$ values for healthy, nonasthmatic, normal weight men ( 17-20 ppb) (Ade et al. 2014; Rosenkranz et al. 2010; Wood et al. 2011). Still, these values were in normal healthy ranges as defined by the American Thoracic Society guidelines. Nevertheless, despite the slightly elevated values while fasted, a HFM appears to provide a sufficient stimulus to increase airway inflammation during the postprandial period. Although the mechanisms explaining the increase in $\mathrm{FE}_{\mathrm{NO}}$ in the postprandial period are not completely understood, they are likely to be due to both TLR4-dependent and TLR4independent pathways (Teng et al., 2014). These pathways converge and lead to an increase in NADPH-oxidases, including NFkB and IKK $\beta$ (Zhang et al., 2005). Therefore high-fat diets may increase NFkB activity (Zhang et al., 2005), may lead to the downstream activation of inducible nitric oxide synthase (iNOS) (Sugita et al., 2002), and subsequent increase in $\mathrm{FE}_{\mathrm{NO}}$ (Gaston et al,. 1994). Additionally, competition for anti-oxidant enzymes after a HFM may inhibit the reduction of $\mathrm{NO}$, resulting in increased $\mathrm{FE}_{\mathrm{NO}}$ in the absence of increased iNOS activity (Bonini et al., 2014). Still, to fully understand the pathways involved, validation with sputum cell counts or directly measured iNOS activity would be needed. In recent work from our laboratory, Kurti et al. (2015) reported the $\mathrm{FE}_{\mathrm{NO}}$ response following a high-fat meal was significant as a quadratic function, and was not significant linearly, indicating an increase at two hours followed by a subsequent return to fasting levels by four hours. The time course is supported by findings at four hours post-HFM from Wood et al. (2011). Kurti and colleagues also reported the increases in $\mathrm{FE}_{\mathrm{NO}}$ were not associated with the change in eosinophils or neutrophils. These findings are likely due to study design where, exercise performed post-HFM may have impacted the neutrophilia in the post-prandial period. Still, the percent increase in $\mathrm{FE}_{\mathrm{NO}}$ relative to values while fasted in the current study $(\sim 18 \%)$ was in agreement with several 
previous studies (Ade et al., 2014, Rosenkranz et al., 2010), and we are confident the increase in $\mathrm{FE}_{\mathrm{NO}}$ is indicative of cellular stress in the airway subsequent to a HFM.

Postprandial lipemia and inflammation

A single bout of moderate exercise performed 12 hours before a high-fat meal has been shown to be effective for attenuating postprandial lipemia (Zhang et al. 1998). Several studies have reported that sedentary men who perform exercise for 30 minutes prior to the HFM show an attenuated PPL response (Murphy, Nevill and Hardman, 2000). Other studies have shown that in contrast to sedentary participants, moderately active individuals need higher energy expenditures to reduce PPL (Brandauer et al., 2013). The 60 min moderate-intensity exercise protocol in the current study did not reduce PPL. Although this duration of exercise has previously been reported to be effective for reducing PPL (Zhang et al., 1998), it is possible the energy expenditure was not high enough given the physical activity habits of our subjects. The review by Katsanos (2004) suggests that an energy expenditure between 600 and $700 \mathrm{kcal}$ may be necessary to see a reduction in PPL for recreationally active individuals. Based on the average body mass of our subjects, the average energy expenditure in the current study was $623 \mathrm{kcal}$. While not statistically significant, it appeared that with our exercise bout there were reductions in postprandial triglycerides when investigating iAUC differences between CON and EX ( $\mathrm{p}=0.075$ and 95 CI's: EX: 51.6219-113.3781 mg/dL; CON: $81.435-171.398 \mathrm{mg} / \mathrm{dL})$. Therefore it is possible we would have seen a statistically significant reduction in PPL with a larger sample size, increasing the energy expenditure during the exercise bout, or by including less active subjects. We did not directly assess physical activity, which is a limitation of the study (see limitations). However, all of our subjects reported planned exercise bouts on at least three days per week and $\dot{\mathrm{V}}_{2}$ values that were slightly higher than those previously reported in our laboratory for recreationally active subjects (Kurti et al., 2015). Still, even will lower postprandial triglycerides in EX compared with $\mathrm{CON}$, there were no significant differences in changes in $\mathrm{FE}_{\mathrm{NO}}$ with changes in triglycerides. This lack of association between triglycerides and $\mathrm{FE}_{\mathrm{NO}}$ suggests that the inflammatory processes that occur in the airway epithelium resulting in the increase in $\mathrm{FE}_{\mathrm{NO}}$, are independent of systemic inflammation, and are likely due to the mechanisms discussed previously.

Although several studies have assessed the effects of a HFM on inflammatory cytokines, our research is the first to report both systemic and airway inflammation after a HFM utilizing an acute bout of moderate intensity exercise 12 hours prior to a HFM. This study adds to the previous literature, contributing to the conflicting results regarding the 
changes in TNF- $\alpha$ and IL-6 post-prandially. While some studies show an increase in TNF- $\alpha$ after a HFM (Nappo et al. 2002), others show a decrease (Blackburn et al. 2006; Payette et al. 2009; Wood et al. 2011). Our data suggest that there is no change in TNF- $\alpha$ four hours after a HFM. Additionally, our finding that IL-6 was unchanged four hours after a HFM is in agreement with some (Blackburn et al. 2006), but not all previous findings (Nappo et al. 2002; Payette et al. 2009; Wood et al. 2011). Although there was no evidence of an effect of a HFM on IL-6 in our study, other findings suggest that IL-6 is not increased until eight hours postprandially (Blackburn et al. 2006; Payette et al. 2009). Because we only measured IL-6 up to four hours postprandially, it is possible that there was a delayed increase in IL-6 that was not accounted for in our study. Also, in a recent study by Ghanim et al. (2009), at four hours post-HFM, NFkB-binding activity increased with no increases in C-reactive protein or TNF- $\alpha$, therefore it is likely the discrepancies in these markers of inflammation are due to the time course in which they are investigated. Also, given that there is large variability in the PPL responses and individual data for inflammatory cytokines, individual differences may often make detecting differences too difficult unless the study has a much larger subject pool. Our primary aim was to determine the post-prandial airway inflammatory response and associations between PPL and inflammation. Given that $\mathrm{FE}_{\mathrm{NO}}$ peaks early, we did not extend our study beyond the four-hour time point. However it is possible we missed the increase in metabolites due to this restricted time period. hsCRP has a delayed response to whole body changes in inflammation. Typically, alterations in hsCRP are detected 16-24 hours after a stimulus (Castell et al. 1997; Petersen and Pedersen 2005). Notably, due to the delayed response of hsCRP, total systemic inflammatory response to the exercise, not the HFM, was intended to be captured at our sampling time points. In agreement with previous literature, no significant difference in change in hsCRP between $\mathrm{CON}$ and EX indicates that there was no overall change in systemic inflammatory status in response to our exercise bout.

Furthermore, our finding that airway inflammation occurred without significant changes in systemic inflammation suggests that the two processes may occur independent of one another. While TNF- $\alpha$, and IL-6 are important mediators of systemic inflammation, other cytokines such as IL-4, IL-5, or granulocyte-macrophage colonystimulating factor (GM-CSF) may be more sensitive indicators of inflammation within the pulmonary system (Busse and Lemanske 2001. Urbano 2007). While TNF- $\alpha$ and IL-6 can indicate the overall systemic inflammatory environment, they are not direct mediators of the airway inflammatory response. However, IL-4, IL-5, and GM-CSF are not typically measured cytokines with regard to systemic inflammation. Our intention was to compare airway 
inflammation $\left(\mathrm{FE}_{\mathrm{NO}}\right)$ with the systemic inflammatory environment with markers commonly used for both acute and chronic exercise training interventions.

Implications

This study further confirms that the airways are sensitive to dietary intake; specifically, consumption of a HFM. Although pulmonary function was unaffected in our non-asthmatic subjects by an acute high-fat meal, Wood et al. (2011) reported a single HFM decreases pulmonary function in asthmatics. Overall, evidence from the current study suggests PPL and airway inflammation after the HFM are not associated, which may have implications for the development of both cardiovascular disease and asthma. Chronically high-fat diets are linked to the development of asthma, and the potential mechanisms may impact the airways independent of the systemic effects of high-fat diets. Additionally, diet may affect the airways regardless of physical activity habits. Future work should determine the airway inflammatory response after exercise in insufficiently active individuals, who may be more likely to display a greater attenuation of PPL after an acute bout of exercise, but are also likely to have reduced protection from oxidative stress due to a lower total antioxidant status.

Limitations

Several factors may have influenced our results. First, sampling of blood lipids was only carried out at three time over a 4 hour period. Although plasma TG concentration typically peaks at four hours (Freese et al. 2014; Gill and Hardman 2003), excluding a sampling point at three hours may have hidden TG peaks in subjects with quicker clearance. Additionally, we are limited in detecting differences in TNF- $\alpha$, IL-6, and hsCRP due to analyzing each sample singly. By analyzing in duplicate we may have increased our ability to detect differences by potentially reducing variability. Also, we were not able to provide details of dietary intake in the days leading up to the HFM in both conditions. Subjects kept this log and verified with the investigator that they consumed the exact same meal in both conditions prior to testing. However we do not have records of their meal intake data. It is possible the protein content of the meal influenced the increase in $\mathrm{FE}_{\mathrm{NO}}$. This would likely be due to nitrates in the meal or L-Arginine consumption (Kharitonov et al., 1997). However the previous literature reports that a much higher level of L-Arginine and nitrates increase $\mathrm{FE}_{\mathrm{NO}}(\mathrm{Olin}$ et al., 2001) and therefore it is unlikely the protein ingestion in our participants (7.01-10.71 grams of protein with approximately $200.7-286.7 \mathrm{mg}$ 
of L-Arginine) was driving the increase in $\mathrm{FE}_{\mathrm{NO}}$. Still, it would have been preferable to measure LArginine and nitrate levels in our participants. Also, it would have been preferable to objectively measure physical activity via accelerometers, however, all subjects indicated on the medical history questionnaire, that they were active for at least 3 days per week. Our meal also consisted of a substantial proportion of carbohydrate (46\%). However, exercise has been shown to be equally as effective for reducing PPL induced by high-carbohydrate, highfat combination meals as for reducing PPL induced by high-fat only. Also, previous studies from our laboratory that have used the same meal showed a significant increase in PPL and $\mathrm{FE}_{\mathrm{NO}}$ following the meal (Rosenkranz et al., 2010; Ade et al., 2014) Lastly, in the typical Western diet, high-fat and high-carbohydrate meals are rarely mutually exclusive.

Conclusions

A high-fat diet has been implicated in the development of chronic levels of airway inflammation associated with the pathogenesis of asthma and other respiratory ailments. Thus far, very little research has evaluated interventions to prevent acute airway inflammation caused by a HFM. To our knowledge, this study is the first to assess exercise prior to a HFM as a possible means to protect against postprandial airway inflammation. Additionally, our study is the first to include systemic markers of inflammation along with measures of airway inflammation and triglycerides in the post-prandial period. Our results provide important insight into the mechanisms involved in postprandial airway inflammation. In our study, there was an increase in airway inflammation in the exercise and control conditions that was not related to the change in triglycerides. The exercise bout lowered PPL, but the decrease was not significant in our group of active subjects. Additionally, our data support previously published work from our laboratory indicating that the severity of airway inflammation following a HFM is uncoupled from the degree of PPL, thus implicating the existence of other mediating processes in the regulation of post-HFM airway inflammation. Future research should aim to identify the specific mechanisms involved in acute postprandial airway inflammation in order to develop effective interventions and assess the potential deleterious effects of frequent highfat meals, particularly in those with airway disease.

Conflict of Interest: The authors declare that there are no conflicts of interest. 
References

Ade, C. J., Rosenkranz, S. K., and Harms, C. A. 2014. The effects of short-term fish oil supplementation on pulmonary function and airway inflammation following a high-fat meal. European journal of applied physiology, 114(4): 675-682.

Beaver, W. L., Wasserman, K. A. R. L. M. A. N., and Whipp, B. J. 1986. A new method for detecting anaerobic threshold by gas exchange. Journal of applied physiology, 60(6): 2020-2027.

Blackburn, P., Després, J. P., Lamarche, B., Tremblay, A., Bergeron, J., Lemieux, I., and Couillard, C. 2006. Postprandial variations of plasma inflammatory markers in abdominally obese men. Obesity, 14(10): 1747-1754.

Bonini, M. G., Dull, R. O., and Minshall, R. D. 2014. Caveolin-1 Regulation of Endothelial Nitric Oxide Synthase (eNOS) Function and Oxidative Stress in the Endothelium. In Systems Biology of Free Radicals and Antioxidants (pp. 1343-1363). Springer Berlin Heidelberg.

Brandauer, J., Landers-Ramos, R. Q., Jenkins, N. T., Spangenburg, E. E., Hagberg, J. M., and Prior, S. J. 2013. Effects of prior acute exercise on circulating cytokine concentration responses to a high-fat meal. Physiological reports, 1(3), e00040.

Busse, W. W, Lemanske, R. F. 2001. Asthma. N Engl J Med 344:350-351-362.

doi:10.1056/NEJM200102013440507

Calder, P. C. 2003. n- 3 Polyunsaturated fatty acids and inflammation: from molecular biology to the clinic. Lipids, 38(4): 343-352.

Castell, L. M., Poortmans, J. R., Leclercq, R., Brasseur, M., Duchateau, J., and Newsholme, E. A. 1996. Some aspects of the acute phase response after a marathon race, and the effects of 
glutamine supplementation. European journal of applied physiology and occupational physiology, 75(1): 47-53.

Freese, E. C., Gist, N. H., and Cureton, K. J. 2014. Effect of prior exercise on postprandial lipemia: an updated quantitative review. Journal of Applied Physiology, 116(1): 67-75.

Gaston, B., Drazen, J. M., Loscalzo, J. and Stamler, J. S. 1994. The biology of nitrogen oxides in the airways. American journal of respiratory and critical care medicine, 149(2): 538-551.

Ghanim, H., Abuaysheh, S., Sia, C. L., Korzeniewski, K., Chaudhuri, A., Fernandez-Real, J. M. and Dandona, P. 2009. Increase in plasma endotoxin concentrations and the expression of tolllike receptors and suppressor of cytokine signaling-3 in mononuclear cells after a high-fat, highcarbohydrate meal implications for insulin resistance. Diabetes care, 32(12): 2281-2287.

Gill, J. M., and Hardman, A. E. 2003. Exercise and postprandial lipid metabolism: an update on potential mechanisms and interactions with high-carbohydrate diets (review). The Journal of nutritional biochemistry, 14(3): 122-132.

Kharitonov, S. A., Alving, K., and Barnes, P. J. 1997. Exhaled and nasal nitric oxide measurements: recommendations. European Respiratory Journal, 10(7): 1683-1693.

Kim, J. J. and Sears, D. D. 2010. TLR4 and insulin resistance. Gastroenterology research and practice.

Kramer, H. F., and Goodyear, L. J. 2007. Exercise, MAPK, and NF-кB signaling in skeletal muscle. Journal of applied physiology, 103(1): 388-395.

Kurti, S. P., Rosenkranz, S. K., Levitt, M., Cull, B. J., Teeman, C. S., Emerson, S. R., and Harms, C. A. 2015. Does moderate intensity exercise attenuate the postprandial lipemic and airway inflammatory response to a high-fat meal?. BioMed research international. 
Kurti, S.P., Smith, J.R., Emerson, S.R., Castinado, M.K., and Harms, C.A. 2015. Absence of respiratory muscle fatigue in high-intensity continuous or interval cycling exercise. J Strength Cond Res. Epub ahead of print. PMID: 25932987

Lowder, T., Dugger, K., Deshane, J., Estell, K., and Schwiebert, L. M. 2010. Repeated bouts of aerobic exercise enhance regulatory $\mathrm{T}$ cell responses in a murine asthma model. Brain, behavior, and immunity, 24(1): 153-159.

Magkos, F., Patterson, B. W., Mohammed, B. S., and Mittendorfer, B. 2007. A single 1-h bout of evening exercise increases basal FFA flux without affecting VLDL-triglyceride and VLDLapolipoprotein B-100 kinetics in untrained lean men. American Journal of PhysiologyEndocrinology and Metabolism, 292(6): E1568-E1574.

Mendes, F. A., Almeida, F. M., Cukier, A., Stelmach, R., Jacob-Filho, W., Martins, M. A., \& Carvalho, C. R. 2011. Effects of aerobic training on airway inflammation in asthmatic patients. Medicine and science in sports and exercise, 43(2): 197-203.

Murphy, M. H., Nevill, A. M., \& Hardman, A. E. 2000. Different patterns of brisk walking are equally effective in decreasing postprandial lipaemia. International journal of obesity, 24(10): 1303-1309.

Nappo, F., Esposito, K., Cioffi, M., Giugliano, G., Molinari, A. M., Paolisso, G., ... and Giugliano, D. 2002. Postprandial endothelial activation in healthy subjects and in type 2 diabetic patients: role of fat and carbohydrate meals. Journal of the American College of Cardiology, $39(7), 1145-1150$.

Olin, A. C., Aldenbratt, A., Ekman, A., Ljungkvist, G., Jungersten, L., Alving, K., and Torén, K. 2001. Increased nitric oxide in exhaled air after intake of a nitrate-rich meal. Respiratory medicine, 95(2): 153-158. 
Payette, C., Blackburn, P., Lamarche, B., Tremblay, A., Bergeron, J., Lemieux, I., ... and Couillard, C. 2009. Sex differences in postprandial plasma tumor necrosis factor- $\alpha$, interleukin6, and C-reactive protein concentrations. Metabolism, 58(11): 1593-1601.

Pellegrino, R., Viegi, G., Brusasco, V., Crapo, R. O., Burgos, F., Casaburi, R. E. A., ... and Wanger, J. 2005. Interpretative strategies for lung function tests. European Respiratory Journal, 26(5): 948-968.

Petersen, A. M. W., and Pedersen, B. K. 2005. The anti-inflammatory effect of exercise. Journal of applied physiology, 98(4): 1154-1162.

Poole, D. C., Wilkerson, D. P., and Jones, A. M. 2008. Validity of criteria for establishing maximal $\mathrm{O} 2$ uptake during ramp exercise tests. European journal of applied physiology, 102(4): 403-410.

Ricciardolo, F. L., Sterk, P. J., Gaston, B., and Folkerts, G. 2004. Nitric oxide in health and disease of the respiratory system. Physiological reviews, 84(3): 731-765.

Rosenkranz, S. K., Townsend, D. K., Steffens, S. E., and Harms, C. A. 2010. Effects of a highfat meal on pulmonary function in healthy subjects. European journal of applied physiology, 109(3): 499-506.

Sugita, H., Kaneki, M., Tokunaga, E., Sugita, M., Koike, C., Yasuhara, S., and Martyn, J. J. 2002. Inducible nitric oxide synthase plays a role in LPS-induced hyperglycemia and insulin resistance. American Journal of Physiology-Endocrinology and Metabolism, 282(2): E386-E394.

Teng, K. T., Chang, C. Y., Chang, L. F., and Nesaretnam, K. 2014. Modulation of obesityinduced inflammation by dietary fats: mechanisms and clinical evidence. Nutr J,13(12). 
Urbano, F. L. 2007. Review of the NAEPP 2007 Expert Panel Report (EPR-3) on Asthma Diagnosis and Treatment Guidelines. Journal of managed care pharmacy: JMCP, 14(1): 41-49.

Wood, L. G., Garg, M. L., and Gibson, P. G. 2011. A high-fat challenge increases airway inflammation and impairs bronchodilator recovery in asthma. Journal of Allergy and Clinical Immunology, 127(5): 1133-1140.

Zhang, X., Dong, F., Ren, J., Driscoll, M. J., and Culver, B. 2005. High dietary fat induces NADPH oxidase-associated oxidative stress and inflammation in rat cerebral cortex.

Experimental neurology, 191(2): 318-325.

Zhang, J. Q., Thomas, T. R., and Ball, S. D. 1998. Effect of exercise timing on postprandial lipemia and HDL cholesterol subfractions. Journal of Applied Physiology, 85(4): 1516-1522. 
Table 1 Subject characteristics

\begin{tabular}{lcc}
\hline Variable & Value & Range \\
\hline Age (years) & $23.0 \pm 3.2$ & $18.4-29.2$ \\
Weight $(\mathrm{kg})$ & $78.5 \pm 11.7$ & $68-108$ \\
Height $(\mathrm{cm})$ & $178.9 \pm 5.5$ & $170-191$ \\
BMI $\left(\mathrm{kg} \mathrm{m}^{-2}\right)$ & $24.5 \pm 2.7$ & $21.4-29.7$ \\
Body Fat \% & $14.3 \pm 4.5$ & $8.2-22.8$ \\
$\mathrm{VO}_{2} \mathrm{max}\left(\mathrm{ml} \mathrm{kg}{ }^{-1} \mathrm{~min}^{-1}\right)$ & $46.9 \pm 7.9$ & $30.2-59.3$ \\
$\mathrm{VT}^{\left(\% \mathrm{VO}_{2} \mathrm{max}\right)}$ & $55.3 \pm 8.2$ & $43.1-71.6$ \\
\hline
\end{tabular}

Values are means \pm SD

$V T$ ventilatory threshold $B M I$ body mass index 
Table 2: Blood analytes

\begin{tabular}{lcccccc}
\hline & \multicolumn{3}{c}{ CON } & \multicolumn{3}{c}{ EX } \\
& Fasting & $2 \mathrm{~h}$ & $4 \mathrm{~h}$ & Fasting & $2 \mathrm{~h}$ & $4 \mathrm{~h}$ \\
\hline TRG $\left(\mathrm{mg} \mathrm{dL}^{-1}\right)$ & $52 \pm 3$ & $97 \pm 38^{*}$ & $89 \pm 23^{*}$ & $70 \pm 20$ & $100 \pm 29^{*}$ & $87 \pm 16^{*}$ \\
$\mathrm{TC}\left(\mathrm{mg} \mathrm{dL}^{-1}\right)$ & $143 \pm 24$ & $150 \pm 25$ & $146 \pm 25$ & $145 \pm 20$ & $143 \pm 19$ & $147 \pm 22$ \\
HDL $\left(\mathrm{mg} \mathrm{dL}^{-1}\right)$ & $44 \pm 4$ & $46 \pm 15$ & $47 \pm 13$ & $45 \pm 11$ & $44 \pm 14$ & $45 \pm 13$ \\
LDL $\left(\mathrm{mg} \mathrm{dL}^{-1}\right)$ & $88 \pm 14$ & $84 \pm 15$ & $83 \pm 19$ & $88 \pm 18$ & $79 \pm 18$ & $84 \pm 19$ \\
Glucose $\left(\mathrm{mg} \mathrm{dL}^{-1}\right)$ & $81 \pm 7$ & $70 \pm 17^{*}$ & $76 \pm 7$ & $78 \pm 7$ & $70 \pm 11^{*}$ & $78 \pm 5$ \\
IL-6 $\left(\mathrm{pg} \mathrm{mL}^{-1}\right)$ & $29.8 \pm 38.0$ & $30.8 \pm 35.5$ & $33.4 \pm 38.7$ & $34.3 \pm 39.5$ & $33.0 \pm 38.6$ & $30.6 \pm 35.2$ \\
TNF- $\alpha\left(\mathrm{pg} \mathrm{mL}^{-1}\right)$ & $6.48 \pm 2.13$ & $6.94 \pm 2.08$ & $7.75 \pm 2.91$ & $6.66 \pm 2.62$ & $6.72 \pm 2.78$ & $7.44 \pm 2.27$ \\
$\mathrm{CRP}\left(\mathrm{mg} \mathrm{L}^{-1}\right)$ & $0.25 \pm 0.32$ & $0.26 \pm 0.43$ & $0.27 \pm 0.45$ & $0.60 \pm 0.96$ & $0.70 \pm 0.83$ & $0.74 \pm 0.92$ \\
\hline
\end{tabular}

Values are means $\pm \mathrm{SD}$

$T G$ triglycerides $T C$ total cholesterol $H D L$ high density lipoprotein $L D L$ low density lipoprotein $I L-6$ interleukin 6 $T N F-\alpha$ tumor necrosis factor alpha $h s C R P$ high sensitivity $\mathrm{C}$-reactive protein

* Significantly different from baseline $(\mathrm{p}<0.05)$ 
Table 3: Pulmonary Function Tests

\begin{tabular}{lcccccc}
\hline & \multicolumn{3}{c}{ CON } & \multicolumn{3}{c}{ EX } \\
& Fasting & $2 \mathrm{~h}$ & $4 \mathrm{~h}$ & Fasting & $2 \mathrm{~h}$ & $4 \mathrm{~h}$ \\
\hline FVC (L) & $5.89 \pm 0.27$ & $5.97 \pm 0.96$ & $5.84 \pm 0.87$ & $6.00 \pm 0.88$ & $5.89 \pm 0.80$ & $5.86 \pm 0.86$ \\
FEV1 (L) & $4.71 \pm 0.62$ & $4.74 \pm 0.60$ & $4.64 \pm 0.57$ & $4.78 \pm 0.60$ & $4.68 \pm 0.57$ & $4.77 \pm 0.59$ \\
FEV1/FVC (\%) & $81.3 \pm 8.5$ & $81.1 \pm 7.4$ & $80.7 \pm 7.7$ & $81.3 \pm 8.7$ & $81.0 \pm 7.7 * *$ & $82.7 \pm 8.7 \neq$ \\
FEF25-75 & $4.54 \pm 1.09$ & $4.55 \pm 0.80$ & $4.43 \pm 0.84$ & $4.58 \pm 0.97$ & $4.57 \pm 0.96$ & $4.78 \pm 1.03$ \\
Rcentral & $0.15 \pm 0.06$ & $0.15 \pm 0.07$ & $0.14 \pm 0.07$ & $0.15 \pm 0.07$ & $0.12 \pm 0.05$ & $0.13 \pm 0.05$ \\
Rperiph & $0.19 \pm 0.08$ & $0.17 \pm 0.09$ & $0.16 \pm 0.08$ & $0.18 \pm 0.10$ & $0.17 \pm 0.09$ & $0.17 \pm 0.10$ \\
eNO (ppb) & $35.7 \pm 23.3$ & $43.1 \pm 25.1 *$ & $40.1 \pm 22.0$ & $37.4 \pm 23.0$ & $43.3 \pm 23.6^{*}$ & $41.1 \pm 23.7$ \\
\hline Val
\end{tabular}

Values are mean $\pm \mathrm{SD}$

$F V C$ forced vital capacity $F E V_{1}$ forced expiratory volume in 1 second $F E F_{25-75}$ forced expiratory flow during 25$75 \%$ of vital capacity $R_{\text {central }}$ central resistance of the airways $R_{\text {periph }}$ peripheral resistance of the airways $F E_{N O}$ fractional exhaled nitric oxide.

* Significantly different from baseline $(\mathrm{p}<0.05)$

$* *$ Significantly different from $4 \mathrm{~h}(\mathrm{p}<0.05)$

₹ Significantly different from CON $(\mathrm{p}<0.05)$ 
Fig. 1. Experimental Design for the control (rest) or experimental (exercise) day. HFM, high-fat meal; PFTs; pulmonary function tests; $\mathrm{FE}_{\mathrm{NO}}$, exhaled nitric oxide; Impulse Osc, impulse oscillometry. PTFs, blood analyses, Impulse Osc. were performed in CON and EX at baseline and then $2 \mathrm{hr}$ and $4 \mathrm{hr}$ after HFM. Participants were resting in the CON condition at the equivalent time to the exercise session.

Fig. 2 Changes in group mean for CON (filled circles) and EX (open circles) for FE $\mathrm{NO}_{\mathrm{NO}}$ after HFM (A) and individual $\mathrm{FE}_{\mathrm{NO}}$ responses for $\mathrm{CON}(\mathrm{B})$ and $\mathrm{EX}(\mathrm{C})$ conditions. Fractional exhaled nitric oxide (airway inflammation) increased $\sim 6.5 \mathrm{ppb}$ from baseline to $2 \mathrm{~h}$ in both conditions. Asterisks significantly different from baseline $(\mathrm{p}<0.05)$. Group data presented as mean $\pm \mathrm{SE}$

Fig. 3 Changes in group mean for CON (filled circles) and EX (open circles) for TG after HFM (A) and individual TG responses for CON (B) and EX (C) conditions. An increase in triglycerides from fasted levels was seen at 2 - and $4 \mathrm{~h}$ in both conditions. Asterisks significantly different from fasted levels $(\mathrm{p}<0.05)$. Group data presented as mean $\pm \mathrm{SE}$

Fig 4. Differences in AUC triglycerides for every subject are displayed by subtracting the EX AUC triglycerides from the CON AUC triglycerides. The difference in AUC triglycerides in the EX was not significant $(\mathrm{p}=0.075)$

Fig. 5 Changes in group mean for CON (filled circles) and EX (open circles) for hsCRP (A), TNF- $\alpha$ (B), and IL-6 (C) after HFM. No significant differences within or between conditions were found. Data presented as mean $\pm \mathrm{SE}$ 
Figure 1. Experimental Design for Day 1 (exercise or rest)

CONTROL

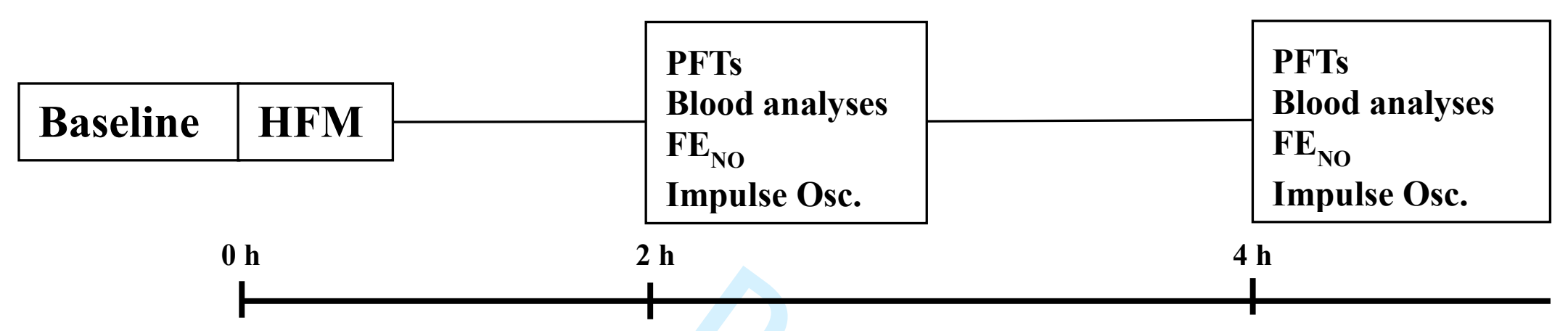

\section{EXPERIMENTAL}

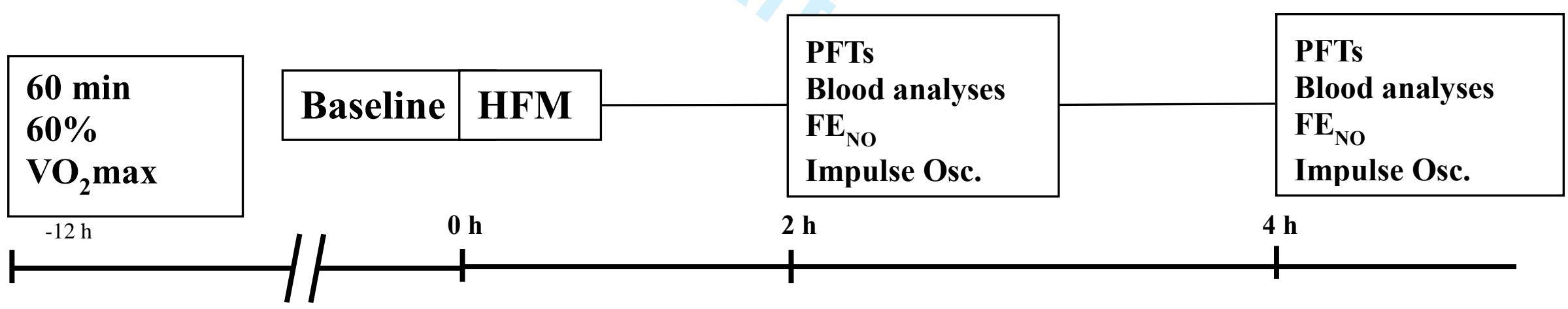



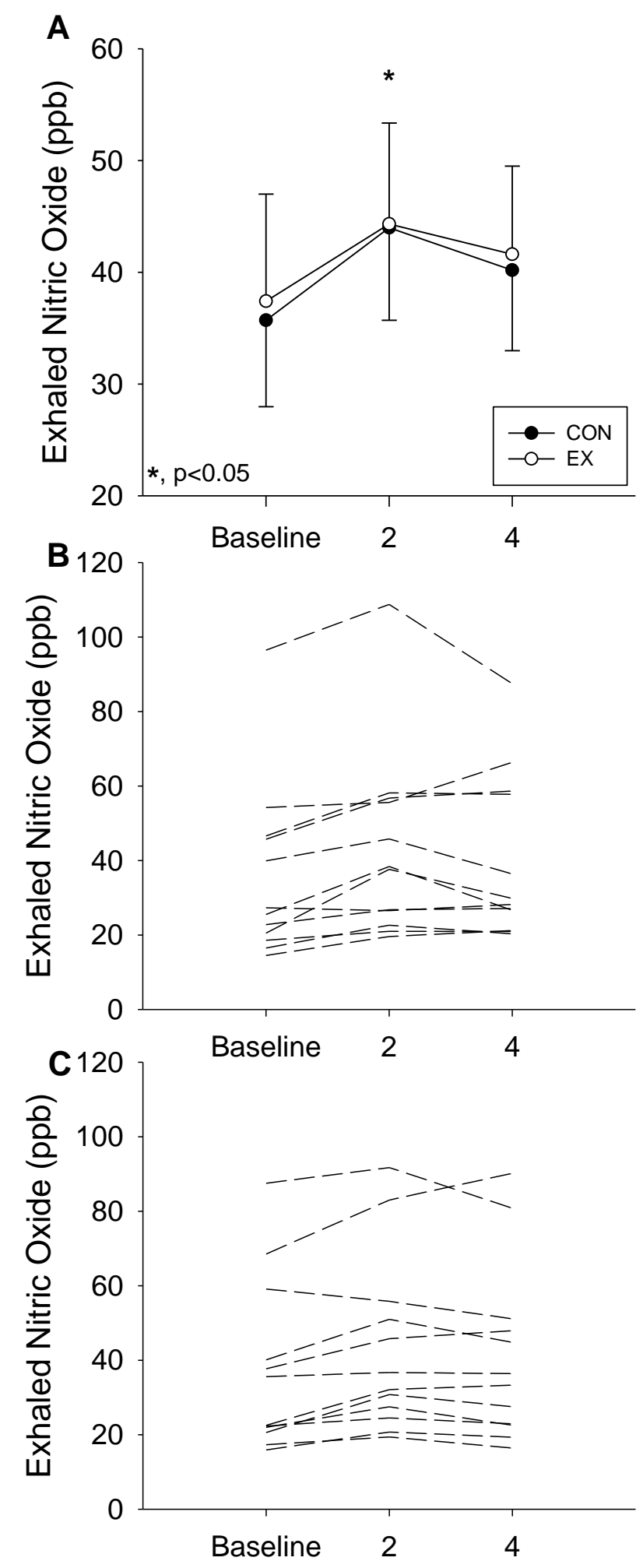


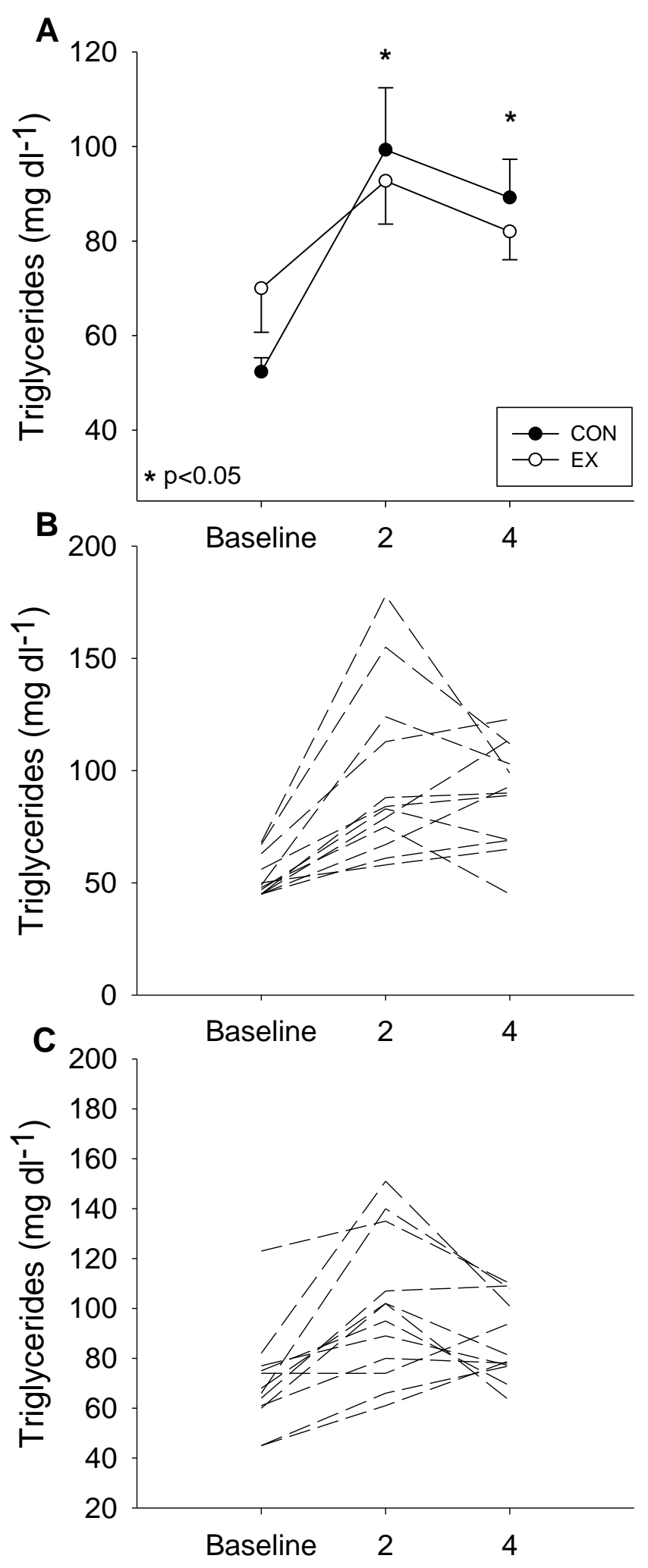




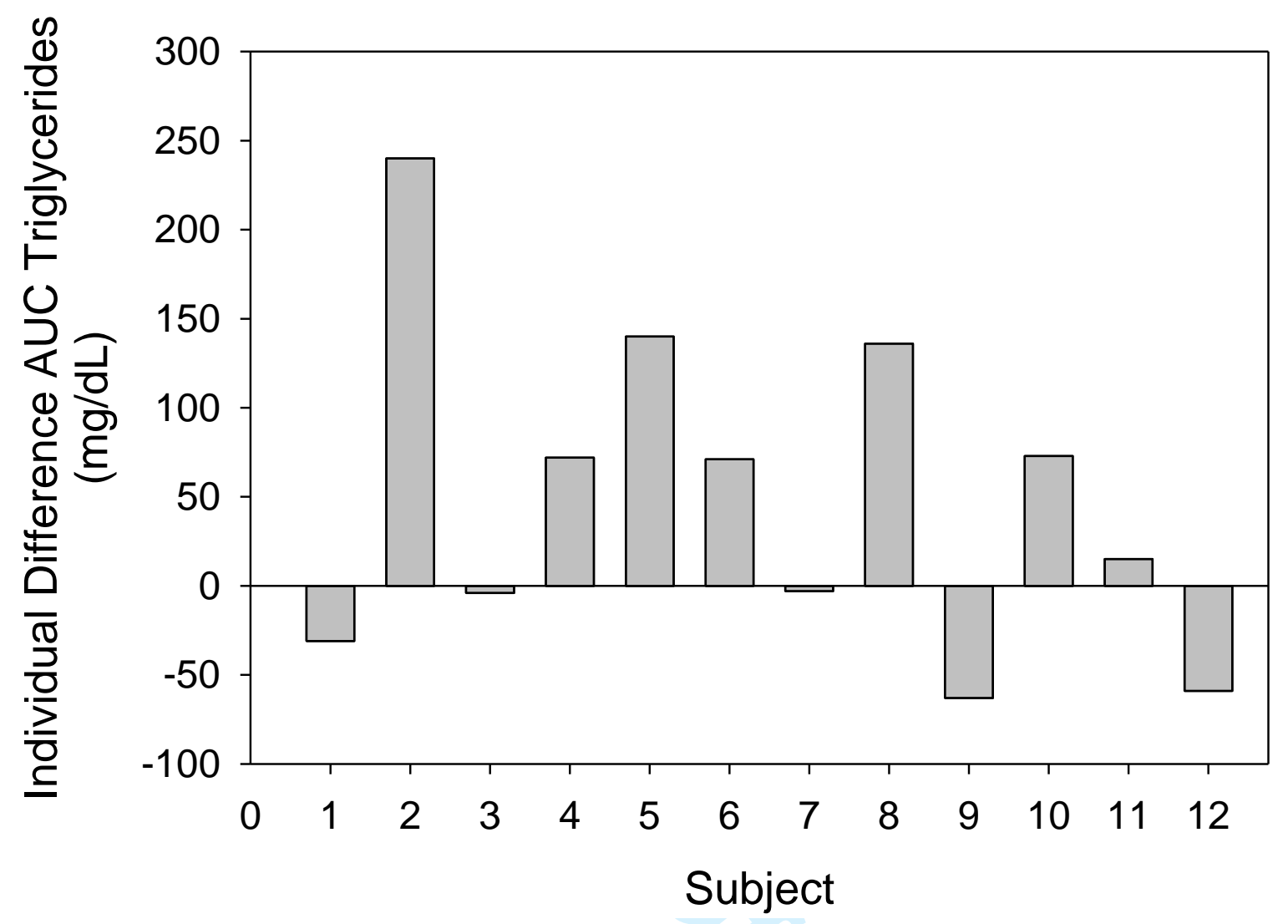



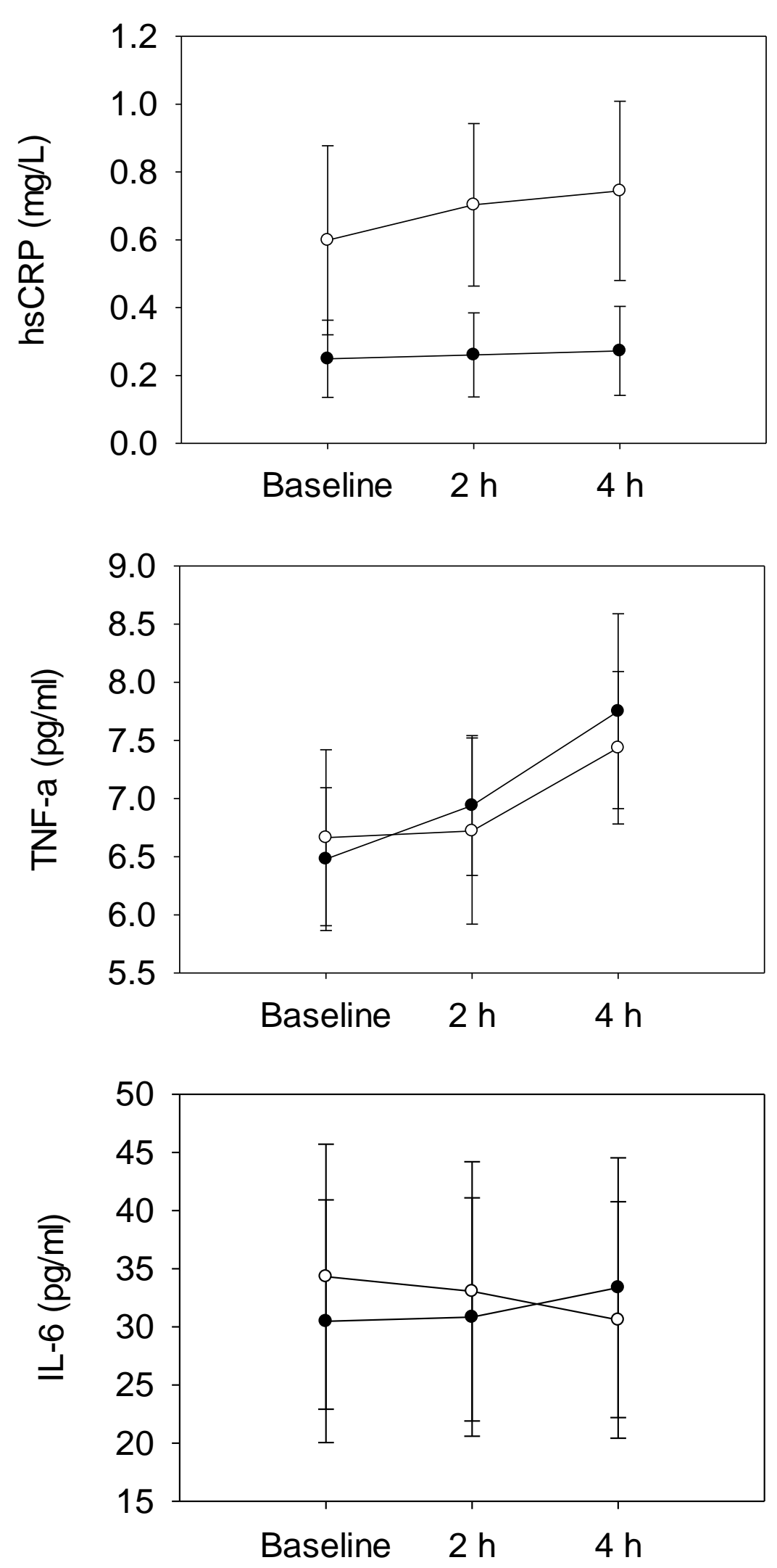